\title{
Filosofía como creación (los complejos vínculos de filosofía y poesía)
}

\author{
EUGENIO TRÍAs ${ }^{1}$
}

\section{1.- Pensar en lengua española}

Quiero ante todo expresar la profunda satisfacción que este Doctorado Honoris Causa me produce, pues constituye para mí un motivo de orgullo recibir esta distinción tan relevante por parte de la decana, en antigüedad y prestigio, de todas las universidades hispanoamericanas, esta hermosa y casi legendaria Universidad de San Marcos que en el día de hoy me acoge como formando parte de su comunidad universitaria.

Esta distinción de la que me siento tan honrado, ha permitido que por vez primera pudiera conocer este querido país, que desde mi infancia y mi juventud había deseado visitar, ya que me unen a él vínculos personales y hasta familiares.

Como he podido relatarlo en un libro reciente de memorias y confesiones que se titula El árbol de la vida, en el que hablo de mis primeros treinta y tres años, y que concluye con la fecha del cambio de régimen en España y del inicio de la transición democrática, toda mi infancia estuvo tutelada y guiada por una abuela materna, Ana Puig-Mir de Sagnier, que había nacido en Guayaquil, donde vivió hasta casi los veinte años; mujer muy culta, amante de todas las artes. Mi abuela siempre consideraba que Lima era su ciudad predilecta; la había conocido en su infancia, y volvió a visitarla siempre que pudo. Era una mujer ecuatoriana enamorada de Lima y de Perú. Y ciertamente me comunicó a mí esos sentimientos, que sin embargo, por diferentes infortunios, me impidieron visitar este querido país en diferentes ocasiones.

El doctor Eugenio Trías Sagnier, uno de los más importantes filósofos españoles del momento, es en la actualidad catedrático de la Universidad Pompeu-Fabra de Barcelona. Fue distinguido como Doctor Honoris Causa por la Universidad de San Marcos el 5 de diciembre de 2003. El texto que publicamos es el del discurso que pronunció en esa ocasión. 
Formamos parte, además, de una misma comunidad lingüística que favorece y facilita los encuentros y los contactos. Nos permite impulsar, en la medida de nuestras fuerzas, lo que considero que constituye una de las grandes tareas del pensamiento filosófico de este naciente siglo y milenio: su desarrollo y despliegue en esa lengua nuestra compartida; una lengua que ha tenido excelentes cultivos en el ámbito de la poesía y de la novela, o en general de la literatura, incluido el ensayo literario; pero que ha sido parca hasta el exceso en sus aventuras lingüísticas y de escritura en un terreno tan sensible para aquilatar los valores y los logros culturales de una comunidad (en este caso, una extensa y compleja comunidad lingüística) como es el ámbito de la creación filosófica.

Y hablo a conciencia de "creación filosófica», pues creo que la filosofía es sobre todo, o ante todo, creación en sentido estricto, poiésis, para decirlo al modo griego y platónico; con el mismo título y con el mismo derecho que la creación en el ámbito de la ficción, o en el terreno literario en sentido amplio.

En filosofía, a diferencia de lo que sucede en el campo de las ciencias, no es prescindible el medio lingüístico en el cual se realiza el trabajo de creación. La investigación científica ha asumido la lengua inglesa como «lengua franca» a través de la cual realiza sus ponencias y aportaciones. Pero en filosofía eso no puede (ni debe) suceder. La filosofía aspira, ciertamente, al conocimiento; pero tiene un carácter creativo que, en relación con el medio oral y escrito en que se expresa, la emparenta a las tradiciones literarias.

Soy de quienes no suscriben incondicionalmente la asimilación de la filosofía a narración o a relato. Creo que la filosofía tiene sus propios modos de argumentar, que no son reductibles a los modos argumentativos de la narración o del poema, como tampoco se pueden subsumir en los que son propios y exclusivos de la ciencia (por ejemplo, de la física teórica, de las matemáticas, de la biología, o de las mismas ciencias humanas o sociales). La filosofía exige la lengua propia del creador, a la cual todo traductor debe acercarse con criterios interpretativos, o hermenéuticos. Uno no puede imaginar el Tractatus en otra lengua que el alemán. Ni puede leer a Peirce, a Foucault, a Ortega y Gasset, a Benedetto Croce o a Heidegger sin tener presente las lenguas originales en que sus textos están escritos. 
La filosofía en su historia ha combinado un género riguroso, bajo el formato del tratado (entronizado por Aristóteles) con un género más ensayístico y cercano a la ficción, sin que ello signifique mengua de profundidad y de exigencia argumentativa, lo cual se advierte ya en los diálogos de Platón, y llega a nuestro siglo a través de grandes escritores y estilistas de la filosofía como Ernst Bloch, Adorno o Benjamin; o bien Foucault y Deleuze.

Importa tener claridad sobre la relevancia de ir gestando y consolidando una tradición y una comunidad filosófica en la que esta impronta de la lengua, en nuestro caso la lengua española, se halle en el centro mismo de nuestras preocupaciones. Sería, creo, un grave error por nuestra parte lanzarse a un insensato universalismo, o a un internacionalismo globalizante, en este sensible terreno de la lengua.

Creo que el universalismo y el carácter internacional de la filosofía se halla en otra parte: en el inventario temático de los asuntos que trata, y en el acopio de medios e instrumentos disponibles para abordar tales asuntos. $\mathrm{Y}$ en esos aspectos sí que importa alzar o elevar la reflexión filosófica en el mundo hispánico a un nivel internacional temático y metodológico que la equipare a otras comunidades.

La filosofía ha de ser universal en sus propuestas; particular en sus formas de expresión, y en el contexto lingüístico en que se realiza; y singular, o radicalmente personal y personalizada, en el estilo propio en que se encarna.

Lo más deleznable de la filosofía de Heidegger radica en su afirmación de que sólo puede pensarse (en el sentido fuerte de la expresión) en lengua griega y alemana. O que de todas las lenguas de la modernidad sólo el alemán destaca por ser en verdad apta para el pensamiento filosófico.

Una afirmación así sólo puede desmentirse en forma pragmática: mostrando formas de pensamiento que se producen en otras lenguas. Creo que ha llegado al fin la hora de las lenguas latinas; y no sólo del francés, con importantes tradiciones filosóficas, desde Descartes a Bergson o a Deleuze, o desde Montaigne a Sartre, sino también del italiano, del español y de otras lenguas de la Latinidad. 
Que la filosofía tenga una pretensión ecuménica y universal no significa que no deba asumir la particularidad del medio expresivo en que discurre. La filosofía nunca ha sido «neutra» en relación con sus formas de dicción. No lo fue en Grecia (Platón es la prueba insigne; pero también Aristóteles); no lo fue en la modernidad; no lo ha sido tampoco en el siglo XX, donde la mejor filosofía se ha puesto a prueba en su estilo, o en la materialidad escrita en que se encarna.

De hecho toda gran filosofía pretende decir o hacer verdad por medio del trabajo ímprobo y riguroso de la escritura y el estilo; y en este punto la filosofía «es la mejor música» (Platón). La filosofía que lo es de verdad no renuncia jamás a constituir un acto de creación (de lo que Platón llamaba poiésis). Sólo la mala y deficiente filosofía hace caso omiso de su materialidad de escritura, o de literatura de conocimiento, manteniendo un criterio «neutro» en relación a esa forja y destilado que constituye el trabajo formal y estilístico del texto.

Un trabajo en el que la creación, o recreación, del filósofo se hermana con la del músico. Por eso la aspiración última del filósofo es extremadamente ambiciosa: proponer Ideas filosóficas que pueden ser asumidas en su posible verdad, pero a través de medios expresivos (lingüísticos o de escritura) que deben evaluarse desde criterios artísticos.

Y eso vale tanto hoy como ayer o anteayer; tiene vigencia en plena modernidad en crisis, en el mundo de cambio de milenio que vivimos, en plena era global; lo mismo que hace quinientos o dos mil trescientos años. Las buenas filosofías son aquéllas que, sobre la base de esos principios, son permeables a los problemas de su tiempo, o saben dar respuestas a éste. Decía Hegel que la filosofía «es la rosa en la cruz del presente».

\section{2.- FiLOSOFÍA Y POESÍA}

Los filósofos debiéramos también, como hacen los poetas, escribir nuestras poéticas: la suerte de preceptiva que hace explícita la pauta interna desde la cual se va gestando una propuesta filosófica. De hecho la esparcimos y desparrama- 
mos por nuestros escritos en los momentos en que se impone razonar y justificar las elecciones conceptuales y de estilo que en cada texto promovemos.

La filosofía, como he adelantado, es un acto de creación, de poiésis. Se halla emparentada con todas las demás formas de creación que bajo el rótulo de Arte o de Literatura se reconocen. La creación no es unívoca; ni admite sólo algunas rutas más o menos canonizadas.

La gran complejidad de la creación filosófica consiste en que debe usar, como la poesía, o la literatura en general, la expresión escrita para poderse producir. No basta el habla, o la «palabra viva», para consumar el acto filosófico. $\mathrm{O}$ no es eso suficiente (al menos desde Platón). Sócrates es, sobre todo, un personaje de ficción; de la ficción platónica tramada en sus extraordinarios diálogos. Es una fabricación (fictio) de la poiésis platónica que asume en muchos de sus diálogos el papel extraordinario con que lo reconocemos. Así nos llega Sócrates a nosotros (con el permiso de Xenofonte).

De hecho entre la escritura y la palabra dialogada discurre lo más genuino de la filosofía, que se despliega en textos de naturaleza literaria (tomando «literatura» en su sentido literal), y que se comenta y potencia a través de la enseñanza oral, o de la exposición verbal, mediante la cual la suerte de propuesta filosófica que se formula puede ser conocida y comprendida, y por lo mismo contrastada y debatida.

La filosofía es literatura de conocimiento. Literatura en la medida en que tiene que ver con la gestación de textos y de escrituras. La textura y la letra no son, en filosofía, objeto de contemplación teorética de una posible «ciencia» (de la escritura y de los textos). Son algo mucho más importante y decisivo: la praxis misma de esa literalidad textual que, en la medida en que se orienta decididamente hacia el conocimiento, puede reconocerse en su identidad filosófica, y en su diferencia específica. Importa esa gramato-praxis como lo más propio y genuino de la filosofía; mucho más que toda inclinación (meta-lingüística) hacia un posible «meta-relato» gramatológico.

La actuación y el ethos del escritor-filósofo es, en esta aventura, lo decisivo; constituye el motor de la creación, o de la poiésis. El filósofo es, desde Platón 
hasta Adorno, desde Aristóteles hasta Wittgenstein, siempre escritor. La escritura le invade y le penetra. Trama, como pedía el poeta español José Ángel Valente de todo verdadero escritor, relación carnal con letras y con grafías. Le importa la disposición de lo que se produce a través de ensayo y estilo. Le importa, por lo mismo, el marco formal en que se dan espacio y tiempo los párrafos, los capítulos, las diferentes partes de este «todo abierto» que acaba cuajando y cristalizando en un texto con su correspondiente título, expresivo de la más secreta intención del compositor.

Pues todo filósofo de verdad es, sobre todo, compositor. Sólo por serlo puede (y debe) ejercer también de intérprete y hermeneuta. Intérprete de sus propias tradiciones, exegeta de los signos de su tiempo, puede componer así una propuesta, o proposición, expresada en forma escrita, que sirva de hilo de Ariadna para abrir el gran laberinto de la recepción dialógica (en el debate, en la enseñanza, en la reflexión verbal acompañada). Inevitablemente debe ser, también, intérprete de su propia propuesta, de manera que ésta alcance el máximo de lucidez y auto-esclarecimiento crítico.

De ahí la necesidad de que todo filósofo, en algún momento de su vida, reflexione sobre su propia forma de situarse en la creación; o de trazar la preceptiva que guía y gobierna, a veces oscuramente, su propia trayectoria y aventura. Pues no se piense que ese proceso irrumpe en toda su diáfana claridad en los procesos de creación, ya que la carga de reflexión trazada en textos se va iluminando, al propio forjador de los mismos, con el paso del tiempo y con el transcurso de la vida. Es más; la sucesión de textos que se añaden a la reflexión, a través de los cuales se intenta consolidar la propuesta filosófica, produce muchas veces una iluminación relampagueante de carácter retrospectivo sobre textos anteriores en el tiempo. Esto sucede en filosofía lo mismo que puede suceder en música o en poesía: el opus 131 (de Beethoven) arroja luz insospechada sobre el opus 18 (pongo por caso).

Olvidar ese carácter creador que posee la filosofía, la filosofía de siempre, la filosofía de hoy y de mañana, es condenarse a enterrarla en la incomprensión y en la mediocridad. Sólo recordando estas verdades tan obvias es posible abrir el gran debate que se espera y desea en el próximo futuro: la relación compleja, tensa (pero amistosa y grandiosa) entre poesía y filosofía. 
Ya que esa reflexión sobre lo textual y lo literario no debe sumirnos en el obtuso logro «postmoderno» de un todo revuelto en el cual todo acaba siendo igual (o «blanco sobre blanco»; allí donde se estrella la refracción cromática de la luz). El «blanco sobre blanco» nos sobrecoge como presión de silencio; y como cerco y acoso de todo lo que nos traspasa.

Pero lo importante e inteligente consiste en trazar las diferencias y las distancias. Sólo desde una distancia apolínea, alciónica, arriba de las más elevadas cumbres (separadas por abismos de hielo), pueden los más amados, filósofos y poetas, encontrarse; o comunicarse en esa distancia que los aboca a un mismo infinito; y que los distingue en sus divergentes estrategias ante un mismo material lingüístico y textual.

En el poeta se destaca en el primer plano escénico de la composición la musicalidad de la expresión verbal y escrita, las medidas del tiempo, los ritmos, la rima interna y externa; y con todo ello también los modos de dar cauce a la elaboración de la materia fónica sobre el cual se expresa y trabaja; o el brotar de imágenes que, en cascada, o a través de explosiones vocales puntuales, van surgiendo del cráter lingüístico, o desprendiéndose del manantial de la lengua. Si bien una misma pasión por conocer, común al poeta y al filósofo, debe asistir a ese parto de las Musas.

Ya que también la poesía aspira a conocer, sólo que con otras estrategias y medios que la filosofía. En ésta también se produce un escondido y esotérico trabajo con la musicalidad de la expresión; también la filosofía precisa imágenes y escenarios; la materialidad de la escritura y de la palabra lo exige. Y no existe palabra ni escritura que no se encarnen, en el más riguroso sentido onto-teológico, en la materialidad del discurso o del diálogo, o del texto literario.

Pero lo que en primer plano debe promoverse es otra cosa; y esa otra cosa se nutre, como de su naturaleza física, de la imagen y del sonido, pero estilizando ambas hacia una radical tensión orientada a la elaboración conceptual.

Por eso en filosofía el ensayo filosófico, cuando lo es de verdad, constituye el género más complejo y más difícil, y el más expresivo también; ya que el ensayo hace tientos con la escritura y el lenguaje con los cuales trabaja de forma 
explícita, pero siempre dejando que asomen, y finalmente se produzcan, verdaderas formaciones conceptuales.

Conceptos sobre algo tan problemático y lleno de enigmas como esos temas que se nos ofrecen en forma de antinomias, así por ejemplo las aporías cosmológicas, antropológicas y onto-teológicas a las que hizo referencia Kant en su primera crítica. De hecho esas Ideas (de una razón que se sabe y debe saberse limítrofe y fronteriza) constituyen el asunto y la materia de la filosofía: ¿Qué podemos conocer? ¿Qué debemos hacer? ¿Qué tenemos derecho a esperar? ¿Qué es el hombre?

En torno al enigma (maravillado) de lo que somos, o de nuestra propia condición, o de ese hecho asombroso y descomunal que nos hace ser algo más que vivientes, es decir, inteligentes, y que muestra la proclividad de nuestra inteligencia por propiciar formas de buena vida o vida buena, pero también de arruinar esa finalidad (que los antiguos llamaban eudaimonía) mediante la inveterada inclinación de ésta a gestar y desplegar «hechos inhumanos» (como el personaje don Gutierre de Calderón de la Barca), en ese enigma se gesta la filosofía.

Se origina, como dijo Platón a través de Sócrates en el Teeteto, merced al asombro. Nace así la filosofía como emoción; la emoción filosófica; que lo es sólo y en la medida en que se vuelve habitual y recurrente, o pasional, ya que la pasión es siempre hábito o disposición (repetitiva) que inviste al sujeto; lo inviste y reviste de costumbre que le constituye y compone.

No hay verdadera filosofía sin estilo, escritura y creación literaria; pero tampoco la hay sin elaborada forja conceptual.

Toda filosofía auténtica posee «aires de familia» que son comunes con la buena poesía; pero no hay filosofía sin la gestación de tramas y urdimbres conceptuales que le permiten la trabazón de una proposición que constituye su hecho diferencia y su seña de identidad.

Sólo que esa retícula de conceptos se halla siempre, a diferencia de la ciencia, al límite mismo de su encuentro con el misterio; y en consecuencia en la frontera misma de lo que puede expresarse y decirse. 
La tensión es máxima. El fruto es sabroso. Ya que de esa tensión puede surgir el juego lingüístico y conceptual en el cual la propuesta filosófica se reconoce.

Nada sería la obra escrita platónica sin la aporética y difícil tensión que la idea de Idea produce; nada Aristóteles sin su terca y maravillosa tensión escrita en torno a la Energía, o al acto enérgico que da consumación y Fin a lo Potencial; nada Hegel sin su Espíritu Absoluto en su capacidad de enajenarse y perderse, y de reencontrarse consigo; nada Heidegger sin su Diferencia Ontológica (o sin su Ser en el Mundo), ni nada Wittgenstein sin su significación de los Límites del mundo a partir del auto-esclarecimiento de los límites del pensamiento en sus formas de expresión verbal (en el más amplio sentido).

Eso no tiene nada que ver con el concepto decimonónico de Sistema sino con la necesaria arquitectónica que la textura filosófica edifica, construye y reconstruye; ésta sólo puede producirse si una articulación estructurada de conceptos desencadena una proposición filosófica.

Que esa propuesta pueda mostrarse operativa en todos los ámbitos o barrios de su elección es, justamente, lo que toda filosofía se ve en la necesidad de poner a prueba; o de experimentar una y otra vez, en confrontación con la experiencia de vida en el más amplio sentido de la expresión. La filosofía es, en este sentido, a la vez unitaria y susceptible de dispersarse y de recrearse en ámbitos bien diferenciados. Posee un doble movimiento y ritmo de expansión y contracción.

Frente a la propensión gremial, favorecida por los cauces burocráticos de la transmisión y de la enseñanza, por parcelar en «áreas de conocimiento» el buen hacer y saber filosófico, es necesario apuntalar la exigencia de unidad en la propuesta en que toda filosofía puede y debe reconocerse. Toda filosofía gravita en torno a una idea matriz, o a una Idea primigenia, en la que asume su máximo compromiso, y también su mayor riesgo y fortuna. Ya que en la experiencia arriesgada ante el peligro crece siempre lo más fecundo y prometedor.

$Y$ esa idea es la que, de un modo u otro, se va mostrando y reconociendo en toda propuesta filosófica que haga válida esta expresión. Una Idea que no puede formularse una sola vez, sino que se va gestando y variando, o recreando, a medida que la aventura filosófica se va produciendo; en el avance mismo de una 
vida comprometida con esa literatura de conocimiento, ensayística y conceptual a la vez, ejercida en el límite de lo que podemos conocer o expresar; y en referencia a lo que se retira y repliega a nuestra percepción y entendimiento; en ese Límite del mundo (o Finis térrea) que constituye, ni más ni menos, el signo y el emblema de nuestra identidad y condición humana; y acaso, o sobre todo, la señal misma de la realidad última e incondicional de lo que Parménides comenzó a pensar como el ser mismo.

Un ser que en mi propia propuesta filosófica puede y debe ser concebido como ser del límite que se va recreando y variando (según el principio que denomino principio de variación; un principio que formalizo según lo que por «variación» se entiende en música).

Ese ser del límite que se recrea constituye, en la filosofia del límite que he ido gestando desde hace ya casi tres décadas, la propuesta filosófica en la que se conceptúa lo que he ido elaborando en diferentes ámbitos o barrios: en los cuatro barrios en que, de manera preferente, puede trazarse la expansión de esa Idea así propuesta (según se consignó en mi anterior libro, Ciudad sobre ciudad).

Los barrios entrecruzados de esta ciudadela del límite son el barrio ontológico-epistemológico (razón fronteriza), el barrio ético-práctico (en interacción con la condición humana), el barrio simbólico-religioso (referido a la Edad del Espíritu) y el barrio simbólico-artístico (con su distinción entre artes fronterizas y apofánticas; o en su reflexión sobre lo bello y lo siniestro; o sobre la relación entre el artista y la ciudad).

Cada uno de ellos posee su propia autonomía relativa; guarda importantes relaciones y diferencias con los restantes; y ninguno está subordinado en relación jerárquica con respecto a los demás. Ni la razón teorética está subordinada a la razón práctica, como creyeron Kant y los kantianos, ni tampoco sucede a la inversa, según el sentir de los clásicos griegos; pero tampoco la religión marca su predominio sobre los demás; ni el arte es, como quería Nietzsche, y el propio Heidegger, el paradigma de un nuevo concepto ontológico de verdad.

La verdad ontológica (relativa al ser del límite que se recrea) debe mostrar la armonía en la discordia entre un renovado concepto de inteligencia y razón (o razón fronteriza) y un nuevo concepto de realidad que permita exhibir en ella el 
mismo juego de categorías que en la razón se descubren. Un juego categorial como el que suelo presentar (en número de siete): el conjunto de determinaciones mediante las cuales la razón accede a la realidad; y a la vez y en el mismo sentido el conjunto (trabado) de determinaciones que la propia realidad ofrece.

Todo esto debe hallarse en primer plano de la reflexión en lo que se refiere a una posible propuesta filosófica expuesta en escritura, o a través de la palabra. Pera esa exposición debe acoger, con el fin de ser permeable a la materialidad misma del pensamiento, que es siempre lenguaje y escritura, también aquellas vibraciones de imagen y musicalidad sin las cuales éste no puede expresarse ni comunicarse.

$\mathrm{Y}$ en este sentido el concepto desplegado debe poseer, en la medida de sus propias posibilidades, antenas poéticas, o tramar consorcio radical (simbólico) con esas dimensiones de la materia encarnada de todo lenguaje y de toda escritura.

Un concepto con permeabilidad a la suerte de sugerencia que, en primer plano, resplandece en toda verdadera poesía sería, pues, la pauta (preceptiva) y la poética filosófica de esta filosofía del límite. Pero esa permeabilidad épica y lírica debe producirse siempre desde la máxima tensión que la conceptuación, encaramada al Límite, o sometida a toda su presión, puede llegar a producir.

De lo contrario la filosofía se derrumba en mala filosofía; mala conceptuación y deficiente poesía; el ensayismo en pura divulgación; o bien el concepto pierde toda su calidad filosófica tornándose abstracto y separado de las fuentes mismas de la vida.

Es falso pensar que el concepto, si es receptivo a la experiencia humana, o si acoge y recoge con prontitud los latidos de la vida y de la existencia, reseque la experiencia y la tergiverse; o que sea incapaz de despertar emociones y hasta pasiones. El buen concepto filosófico logra esto con creces. Y por eso el entendimiento cabal de las mejores propuestas filosóficas produce una profunda emoción (estética y pasional). Puede llorarse de alegría el día en que se descubre, con emoción difícil de contener, la verdad desplegada en una propuesta filosófica; cuando se llega a comprender de verdad una filosofía (la de Aristóteles, la de Spinoza, la de Leibniz, pongo por caso). 
Y es que la inteligencia no es sólo facultad de dominación, o de expresión de lo que Agustín de Hipona llamaba libido dominandi. Estilizada en la mejor conceptuación filosófica la inteligencia halla en esa literatura de conocimiento un modo de expresión de la mejor verdad humana; y una gesta épica de desafío y riesgo en torno al misterio que nos rodea, situado al filo mismo del Límite entre lo accesible a nosotros y el Arcano.

La poesía puede proveerse de argumentación filosófica para suscitar su chisporroteo de imágenes, ritmos y rimas (así en los Cuatro cuartetos de Eliot, donde el unísono argumental de una lección magistral filosófica sobre el tiempo sirve de basso continuo que permite la conjugación de Muchas Voces; Muchas Voces y Muchos Dioses, como el Mar).

Pero en filosofía la relación se invierte por necesidad; las imágenes, los sonidos, el repicar de la campana (que anuncia un tiempo anterior a nuestro tiempo de vida), todo ello constituye el material verbal sin el cual no puede levantar el vuelo la voz siempre plural, siempre compleja, en que una propuesta filosófica, unitaria y diversificada a la vez, llega a articularse y desarrollarse.

\section{3.- LA PROPUESTA DE UNA FILOSOFÍA DEL LÍMITE}

Creo que toda innovación en filosofía consiste en desplazar el centro de gravedad de los conceptos principales que la componen, o en trasladar al centro algún concepto que suele hallarse muchas veces en la periferia de las nociones o ideas que en toda filosofía se manejan. En cierto modo se trata de dar cumplido uso a aquella vieja expresión profética vetero-testamentaria que se recoge en los evangelios sinópticos: «La piedra desechada será convertida en piedra angular».

Toda innovación en filosofía, toda inauguratio de un nuevo cosmos de Ideas filosóficas, responde casi siempre a ese peculiar desplazamiento. Se trata, pues, de que aflore algo que, por la razón que sea, no suele emerger ante la conciencia reflexiva filosófica; o que sólo lo hace de forma eventual, sin que se le asigne un papel central en el marco conceptual y discursivo que se propone. Los ejemplos podrían multiplicarse (hasta recorrerse la historia entera de las ideas filosóficas). El 
«jeureka!, ;Lo encontré!», se produce en filosofía siempre a través de ese peculiar desplazamiento del centro y de la periferia (del edificio que componen las ideas).

Por eso lo propio de la actividad filosófica consiste en promover un desplazamiento de esta índole, y en cobrar conciencia respecto a que en ese pulso que se ejerce sobre las ideas radica toda pretensión de innovación. Si tal desplazamiento tiene lugar, y sobre todo si se muestra de modo argumental el trayecto y recorrido (metódico) que tal modificación del centro de gravedad produce, entonces debe hablarse de innovación, por mucho que se escatime o regatee esa expresión en razón de coyunturas ambientales. La distinción entre una filosofía creadora, portadora de su propia propuesta, y otra simplemente tardía, radica en este sensible punto.

Esa propuesta puede sufrir todas las influencias que se quieran; puede echar mano de ideas o conceptos de toda la vida; pero lo importante es que aquellas influencias queden trascendidas y subsumidas en el nuevo centro de gravedad que se ofrece; y que esos conceptos de siempre queden totalmente renovados y rejuvenecidos en razón de la savia nueva que les infunde ese nuevo centro gravitatorio, o el concepto que asume dicho centro. Así mismo esa propuesta debe abrirse al contraste que sólo la discusión y el debate filosófico puede garantizar, único modo de convalidar el fuste y la fortaleza de la proposición a la que se intenta dar expresión.

Ese desplazamiento (del centro de gravedad, o de la relación entre centro y periferia) debe ser de tal orden que por su sola modificación cambie y transforme, una por una, las grandes ideas y las grandes cuestiones en que suele discurrir la filosofía: las relativas al concepto de ser y de realidad, o de existencia, que podemos hacernos; o al concepto de razón, pensamiento y lenguaje; o de lo que podemos conocer; o de lo que debemos hacer; o de las formas de producción o poiésis; o de los modos de orientarse en relación con lo sagrado; o bien, por último, en relación a nuestra propia condición (humana).

Todas estas cuestiones y problemas, puestas bajo la presión del nuevo campo gravitatorio que se erige entonces como centro compositivo de la propuesta filosófica y de su cumplida exposición, deben ser convenientemente redefinidas y modificadas en su estatuto propio en razón de la polarización que 
dicho campo provoca. En cierto modo el concepto que mejor nombra o expresa ese centro gravitatorio nuevo que hace circular el conjunto de las ideas que nuestro pensamiento puede pensar (y que nuestro lenguaje es capaz de expresar) da una pista decisiva respecto a lo que he llamado el primer requisito de que algo sea propiamente filosofía: su forma argumental. He adelantado que ésta deriva de la correcta elección de un dato concebido como punto de partida o como comienzo, plenamente justificado, que permita dar curso a la modalidad filosófica de argumentar, en virtud de la cual se puede dar un trazado viario y discursivo a la filosofía, o como suele decirse un método (que en griego significa orientación o dirección respecto al camino que se traza).

Ese concepto nuclear que se desplaza de la periferia al centro debe resplandecer de algún modo en la elección del dato del comienzo, y debe guiar en consecuencia el itinerario que a partir de ese arranque puede producirse. Una interna corriente de complicidad debe siempre existir en ese comienzo por el cual se opta y ese centro de gravedad que permitiría, en virtud del reconocimiento de su naturaleza y esencia, una posible composición filosófica, o una edificación (en el sentido en que Kant habla de «arquitectónica» de la razón pura) que permita mostrar, de forma clara y ostensible, la innovadora propuesta filosófica que se ofrece.

Lo propio de la filosofía es generar esa mostración a través de la forma argumentada en que, arrancando de un determinado punto de partida o comienzo, se va promoviendo un trazado, un método, con sus hitos propios, con sus jornadas, «singladuras» o «días» que lo componen. Tales hitos son las determinaciones conceptuales de ese trazado (o si quiere decirse de forma clásica, sus categorías).

Ese centro de gravedad lo es siempre de algún astro celeste o de alguna estrella; la que orienta la actividad filosófica (del mismo modo como una estrella orientaba, en su día, a los reyes magos procedentes de Irán, que eran «magos helenizados»)).

Tal estrella visible, siempre abierta a la comprensión y a la inteligencia propia de la filosofía, es la propuesta de sentido (y por ende de razón, de logos) que la filosofía en cuestión propone. Y esa propuesta de sentido viene determinada 
por el campo gravitatorio en el cual se expresa, de modo diferenciado, en razón del aludido desplazamiento, una nueva concepción del ser.

En lo que a mi propuesta filosófica se refiere, ese campo gravitatorio lo constituye el ser del límite; es decir, un modo propio y específico por redefinir y recrear lo que por ser se entiende desde Parménides, Platón y Aristóteles.

Y lo que en torno a ese campo gravitatorio gira o danza no es una estrella sino un sistema binario. Se trata de la estricta danza, de cuyos ritmos deriva en gran medida la eventual narración histórica que puede trazarse del ser del límite, entre una estrella doble, o una doble figura estelar; dos estrellas entrelazadas en virtud de la peculiaridad misma del campo gravitatorio que determina la propia entidad y movimiento de esos astros luminosos. A esas estrellas binarias les llamo la razón fronteriza (que es la suerte de logos que co-responde al ser del límite) y el suplemento simbólico (que es la suerte de forma expositiva que puede dar cuenta del excedente inherente a la naturaleza limítrofe del ser).

Mi propuesta filosófica compone un triángulo con sus tres vértices: un vértice, el que forma ángulo recto, expresa o nombra mi propuesta relativa al ser (que es la idea de ser del límite). Uno de los dos vértices agudos expresa mi propuesta relativa al sentido del ser (que es mi idea de razón, o logos, de carácter fronterizo); y el otro vértice nombra mi propuesta relativa a la posible exposición (siempre supletoria o vicaria) de lo que excede el ser del límite. Una exposición que es «indirecta y analógica» (según el decir de Kant), y a la que llamo símbolo.

El triángulo está, pues, formado por el ser del límite, la razón fronteriza y el suplemento simbólico. Lo importante es comprender que esos tres ángulos del triángulo, o esos tres términos y conceptos, se hallan estrictamente entrelazados. O que se definen unos por los otros, de manera que en esa interrelación se altera radicalmente lo que esos términos pueden expresar en otras constelaciones filosóficas o teóricas.

Una razón que se asume como razón fronteriza o limítrofe marca, pues, sus distancias con respecto a otras formas de definir la razón (por ejemplo, como razón comunicativa, como razón analítica, como razón dialéctica o como razón narrativa). 
Un suplemento simbólico que asume la condición limítrofe del ser y de la razón se distancia radicalmente de otras teorías del simbolismo (como las propias de las filosofías de la religión de este siglo, o de las «psicologías profundas» de Jung y sus seguidores, o de Mircea Eliade y otros miembros del Círculo de Éranos). Y una concepción del ser como ser del límite, que exige una razón redefinida como razón fronteriza (y un suplemento simbólico fecundado por esta inspiración limítrofe) marca sus distancias con otras ontologías o metafísicas relativas al ser, como la que piensa la diferencia entre el ser y el ente (Heidegger), o en general todas aquéllas que gravitan en torno a la Diferencia (o a lo que Gianni Vattimo denomina «las aventuras de la diferencia»).

Entre el ser del límite (que define y determina el campo gravitatorio) y esas dos estrellas binarias que giran en torno a él (la razón fronteriza y el suplemento simbólico) se instituye una propuesta que tiene la pretensión de desplazar el orden de ideas y conceptos que componen nuestro pensamiento. Mi pretensión filosófica consiste en promover un desplazamiento en esos hábitos y creencias que configuran nuestras rutas de pensamiento y raciocinio, o nuestras disposiciones mentales (que acaban constituyendo simples creencias, como sabía Ortega y Gasset). 